\title{
Development of a piezoelectric energy harvesting sensor: from concept to reality
}

\author{
Konstantinos Gkoumas \\ Sapienza University of Rome (now at European Commission, Joint Research Centre) \\ konstantinos.gkoumas@uniroma1.it, bttps://orcid.org/0000-0003-3833-6223 \\ Franco Bontempi \\ Sapienza University of Rome \\ franco.bontempi@uniroma1.it, bttps://orcid.org/0000-0001-6377-7501
}

\begin{abstract}
This study focuses on the development and integrated design over a 24-month period of a high efficiency Energy Harvesting (EH) temperature sensor, based on piezoelectric materials, with applications for the sustainability of smart buildings, structures and infrastructures. The EH sensor, harvests the airflow inside Heating, Ventilation and Air Conditioning (HVAC) systems, using a piezoelectric component and an appropriate customizable aerodynamic fin that takes advantage of specific air flow effects, and is implemented for optimizing the energy consumption in buildings. The project is divided in several work-packages (some running in parallel) that cover different aspects of the device development. Some of them focus on engineering aspects (starting from the numerical modeling, then prototyping, and concluding with experimental testing). Other aspects focus on the sensor promotion (including the development of a business plan, the intellectual property rights, the final design and the go-to-market actions). Considering the multidisciplinary character of the project (involving knowledge from fields such as wind engineering, electrical engineering, industrial design, entrepreneurship), this study tries to provide an insight on the complex design issues that arise when such complex, sometimes conflicting and overlapping aspects have to be managed within strict deadlines. In doing so, the most important design and development aspects are critically presented.
\end{abstract}

KEYWORDS. Energy harvesting; Prototyping; Temperature sensor; HVAC; Smart buildings; Project management.

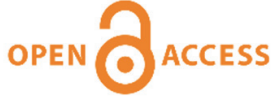

Citation: Gkoumas, K., Bontempi, F., Development of a piezoelectric energy harvesting sensor: from concept to reality, Frattura ed Integrità Strutturale, 47 (2019) $150-160$.

Received: 21.08.2018

Accepted: 18.10 .2018

Published: 01.01.2019

Copyright: (C) 2019 This is an open access article under the terms of the CC-BY 4.0, which permits unrestricted use, distribution, and reproduction in any medium, provided the original author and source are credited. 


\section{INTRODUCTION}

$\mathrm{E}$

ngineers, designers and planners, are nowadays very sensitive to issues related to the sustainability of structures. To this end, one of the primary aims of civil engineering design in particular, is to conceive and build structures with low environmental impact and with an optimal energy performance. As a consequence, in the last few decades, the concept of Smart Building was born. This requires buildings equipped with additional subsystems for managing and controlling energy sources and house appliances, and minimize energy consumption, often using wireless communication technology [1-2]. Among these, typical examples are Building Automation Systems, or centralized, interlinked networks of hardware and software that monitor and control the environment in commercial, industrial, and institutional facilities. One of the objectives of Building Automation is to automatize the systems in the building through the monitoring of ambient parameters using properly installed sensors. These sensors can be powered through the mains or in alternative, can be selfpowered. The latter is advantageous because it makes their installation easier, it reduces the cost of cabling and increases the efficiency in maintenance. An alternative is the use of batteries, which, however, considering their limited lifetime, need to be replaced at regular intervals. Thus, in addition to having a high environmental impact, their use affects maintenance costs in the long term. Therefore, the best solution is to employ wireless autonomous sensors powered by Energy Harvesting $(\mathrm{EH})$ devices.

Regarding the latter, energy harvesting, i.e. the process of extracting energy from the environment or from a surrounding system and converting it to useable electrical energy, is a prominent research topic, with many promising applications nowadays in buildings, transportation infrastructures and bridges, mainly for structural health monitoring (SHM) applications [3-4]. Its areas of application are currently focused - though not limited - to powering small autonomous wireless sensors (thus eliminating the need for wires), while more recently proposals have been made concerning higher power energy harvesting devices, in the upward trend of renewable energy growth.

Regarding applications for building automation, the trend is very positive in the last years, especially after issues regarding the wireless network frequency allocation have been resolved.

This study focuses on an advanced autonomous sensor for the temperature sensing in building HVAC (Heating, Ventilation and Air Condition) systems. It consists in an energy harvesting device that uses a piezoelectric bender and an appropriate customizable aerodynamic appendix that takes advantage of specific airflow effects (vortex shedding and galloping) for producing energy. This kind of flow is typical in HVAC networks. The sensor is completed with a temperature probe, a wireless module and an USB dongle receiver (Fig. 1).

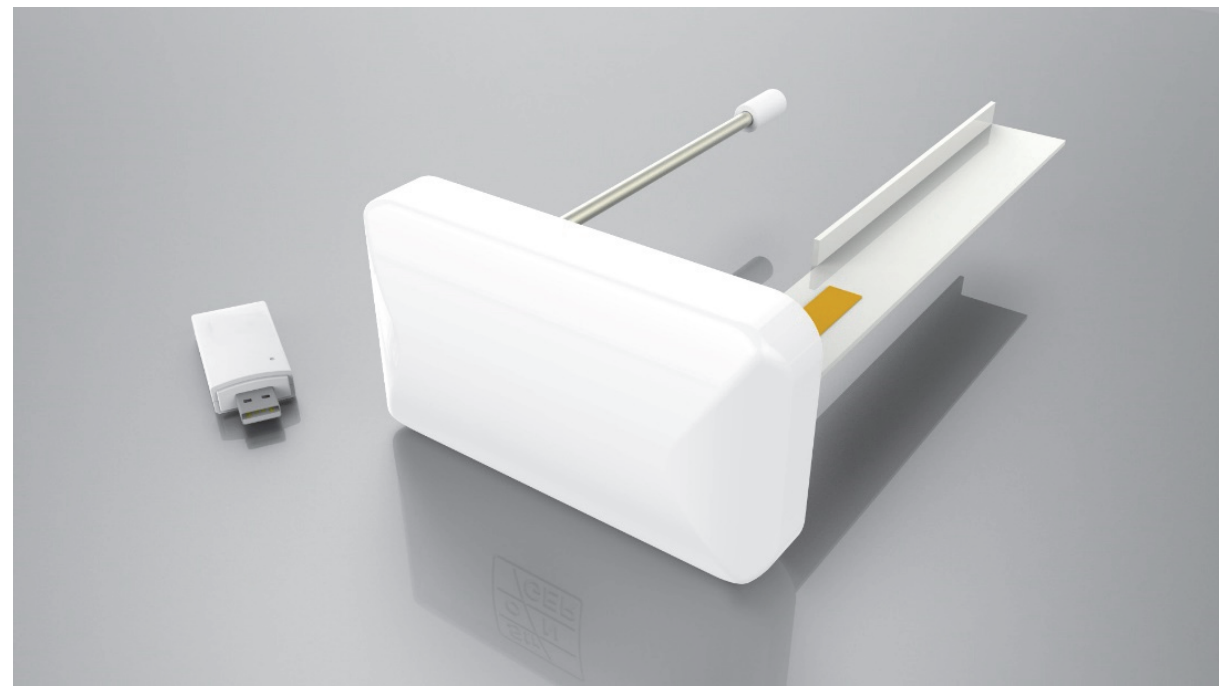

Figure 1: Rendering of the sensor and of the dongle.

The sensor has been thoroughly developed and the technology has been validated over a 24-month period within the ESA (European Space Agency) space technology transfer program at the Business Incubator Center (BIC) Lazio, and its harvesting potential has been demonstrated analytically, experimentally and in close to real conditions [5-6]. The development included exhaustive FEM (Finite Element Method) and Multi-physics (CFD- Computational Fluid Dynamics) analyses, building different prototype configurations, extensive (over 10 sessions) wind tunnel testing at the CRIACIV wind 
tunnel facility in Florence, optimization of the EH circuit, and industrial design. A process to secure the intellectual property rights in the European Union has begun and will be pursued further in the near future. The activities were divided in eight tasks (work packages) developed in the 24 months as shown in Tab. 1. For each task, the planned and the actual months of involvement are indicated, together with the percentage of the actual versus planned activities in terms of months. A midterm review of the project took place after the $12^{\text {th }}$ month. As can be seen from the table, the first two tasks focusing on the numerical modelling and the prototyping were extended in the updated plan, something that highlights the difficulties encountered in these tasks.

\begin{tabular}{|c|c|c|c|c|c|c|c|c|c|c|c|c|c|c|c|c|c|c|c|c|c|c|c|c|c|c|}
\hline \begin{tabular}{|l|}
$\begin{array}{l}\text { Task/ } \\
\text { WP }\end{array}$ \\
\end{tabular} & Task Name & Month & 1 & 2 & 3 & 4 & 5 & 6 & 7 & 8 & 9 & 10 & 11 & 12 & 13 & 14 & 15 & 16 & 17 & 18 & 19 & 20 & 21 & 22 & 23 & 24 \\
\hline \multirow{2}{*}{1} & \multirow{2}{*}{$\begin{array}{l}\text { Numerical } \\
\text { modelling }\end{array}$} & $\mathrm{P}$ & & & & & & & & & & & & & & & & & & & & & & & & \\
\hline & & A & $325 \%$ & & & & & & & & & & & & & & & & & & & & & & & \\
\hline \multirow{2}{*}{2} & \multirow{2}{*}{ Prototyping } & $\mathrm{P}$ & & & & & & & & & & & & & & & & & & & & & & & & \\
\hline & & $\mathrm{A}$ & $200 \%$ & & & & & & & & & & & & & & & & & & & & & & & \\
\hline \multirow{2}{*}{3} & \multirow{2}{*}{$\begin{array}{l}\text { Experimental } \\
\text { Testing }\end{array}$} & $\mathrm{P}$ & & & & & & & & & & & & & & & & & & & & & & & & \\
\hline & & A & $75 \%$ & & & & & & & & & & & & & & & & & & & & & & & \\
\hline \multirow{2}{*}{4} & \multirow{2}{*}{\begin{tabular}{|l|} 
Final Design \& \\
Prototype
\end{tabular}} & $\mathrm{P}$ & & & & & & & & & & & & & & & & & & & & & & & & \\
\hline & & A & $100 \%$ & & & & & & & & & & & & & & & & & & & & & & & \\
\hline \multirow{2}{*}{5} & \multirow{2}{*}{ Business Plan } & $\mathrm{P}$ & & & & & & & & & & & & & & & & & & & & & & & & \\
\hline & & $\mathrm{A}$ & $450 \%$ & & & & & & & & & & & & & & & & & & & & & & & \\
\hline \multirow{2}{*}{6} & \multirow{2}{*}{\begin{tabular}{|l|} 
Intellectual \\
Property Rights
\end{tabular}} & $\mathrm{P}$ & & & & & & & & & & & & & & & & & & & & & & & & \\
\hline & & A & $100 \%$ & & & & & & & & & & & & & & & & & & & & & & & \\
\hline \multirow{2}{*}{7} & \multirow{2}{*}{ Marketing } & $\mathrm{P}$ & & & & & & & & & & & & & & & & & & & & & & & & \\
\hline & & $\mathrm{A}$ & $100 \%$ & & & & & & & & & & & & & & & & & & & & & & & \\
\hline \multirow{3}{*}{8} & \multirow{2}{*}{ Management } & $\mathrm{P}$ & & & & & & & & & & & & & & & & & & & & & & & & \\
\hline & & A & $100 \%$ & & & & & & & & & & & & & & & & & & & & & & & \\
\hline & & & $\mathrm{KM}$ & & & & & & & & & & & MR & & & & & & & & & & & & FR \\
\hline
\end{tabular}

A

P: Planned, A: Actual, KM: Kickoff Meeting, MR: Midterm Review, FR: Final Review

Table 1: Timeline and work packages of the project development.

A literature review is outside the scope for this study and the reader is referred to [7] and [8] for a review of energy harvesting methods and devices. Nevertheless, two relevant studies are worth citing. Wu et al. [9] developed a cantilever attached to piezoelectric patches and a proof mass, for wind energy harvesting from a cross wind-induced vibration. Weinstein et al. [10] conducted an experimental study of a cantilevered piezoelectric beam excited in a HVAC duct. In their case, the excitation is amplified by the interactions between an aerodynamic fin attached at the end of the piezoelectric cantilever and the vortex shedding downstream from a bluff body placed in the airflow ahead of the fin-cantilever assembly. They concluded that the addition of this fin to the tip of the piezoelectric bender improves significantly the power generation of a vortex shedding induced energy harvester. The power generation in the range of 100 to $300 \mu \mathrm{W}$ for flow speeds in the range of $2-5 \mathrm{~m} / \mathrm{s}$ are sufficient for powering a sensor node of HVAC monitoring systems or other sensors for smart building technologies.

\section{SENSOR DEVELOPMENT PHASES AND PRINCIPAL TIMELINE}

7 he project officially started on February 25 2014. It was endorsed by StroNGER srl, an academic spinoff small medium enterprise (SME) that operated from 2012 to 2017 in the field of Civil and Environmental Engineering.

The project was a natural outcome of research carried out in the period 2012-2014 in energy harvesting by the principal investigators [11-15]), including the organization of a special session in an international conference [16].

On November 2013, an application was made for a 50.000€ grant in the ESA-BIC (European Space Agency Business Incubator Center) Lazio for the space technology transfer. The call focused on space technology applications on earth. The link was the piezoelectric materials, implemented initially in space applications (as transducers). The proposal was successful and the sensor development took place over a period of 24 months, from March 2014 to April 2016. The team behind this research worked closely with ESA-BIC experts and renowned researchers in the fields of aerodynamics and electronics. 
Additional numerical models were built by a fluid-structure interaction expert. The sensor was thoroughly tested over a period of 12 months in wind tunnel at the UNIFI-CRIACIV (the Inter-University Research Center for Building Aerodynamics and Wind Engineering in Florence). The electric circuit was designed with the collaboration of the Sapienza University of Rome. The final design was carried out together with an Italian startup company. Fig. 2 shows the final sensor prototype and its components.

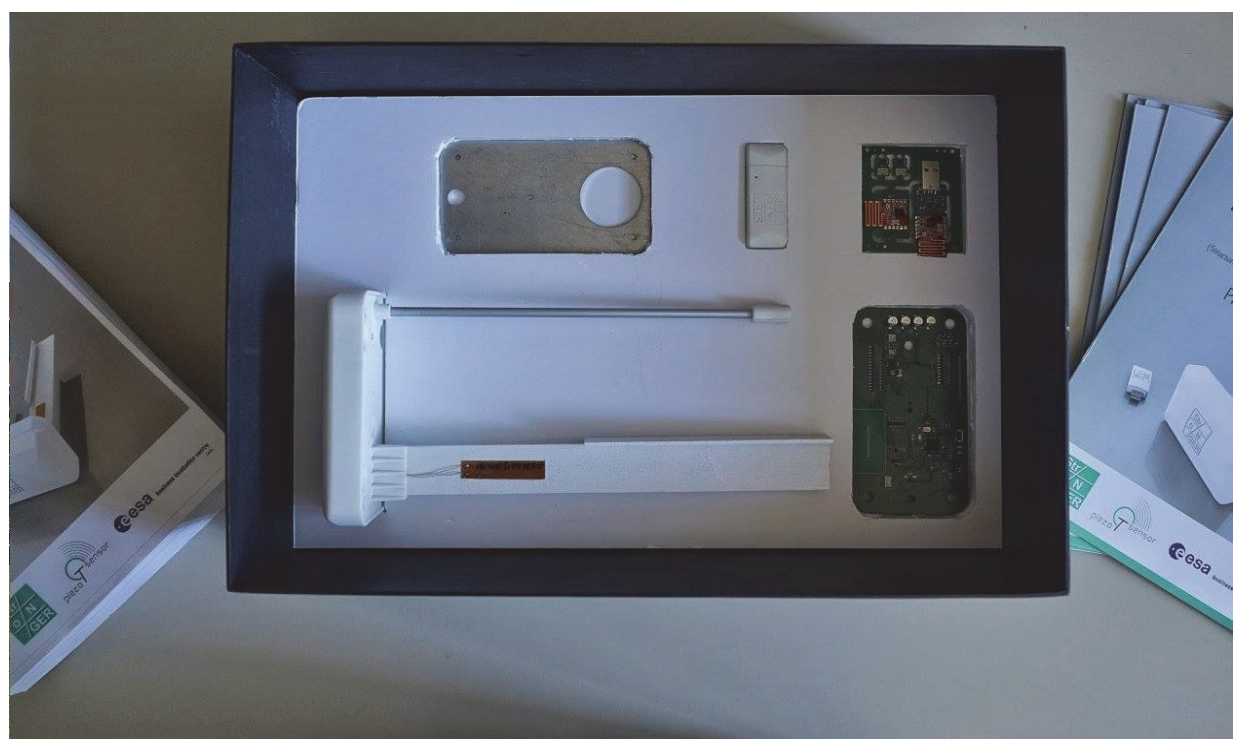

Figure 2: Sensor prototype inside its box.

\section{MODELING ACTIVITY AND PROTOTYPING}

he sensor has been tested extensively and specific aspects have been optimized, starting from the aerodynamic fin form, the materials, and the electronic circuit. Several testing steps have been successfully concluded, focusing on the energy harvesting optimization, including the testing of different harvesting circuits. Numerous numerical models have been developed both in FEM and CFD (Fig. 3), and different prototypes for the aerodynamic fin have been prepared (Fig. 4). For more information regarding the adopted methodology and numerical modeling activity, the reader is referred to [17-18].
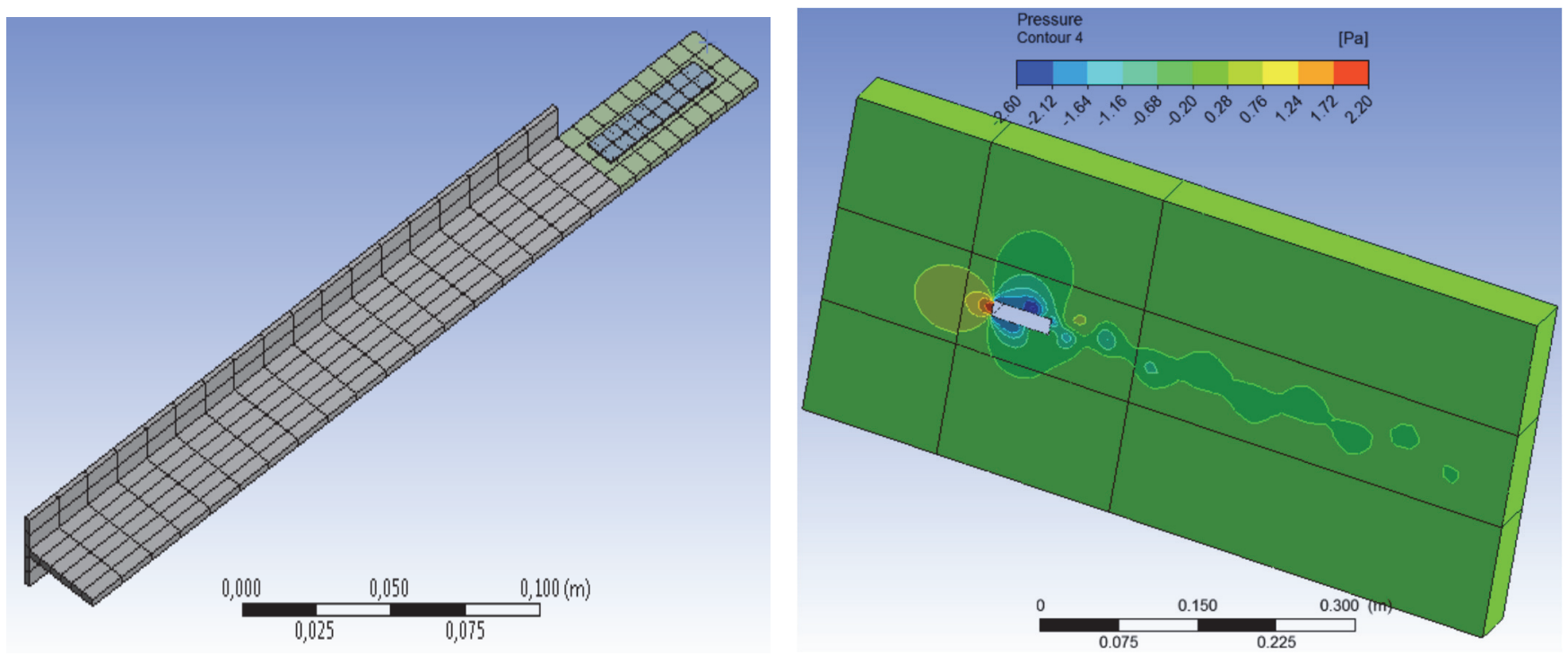

Figure 3: FEM and CFD models of the sensor. 


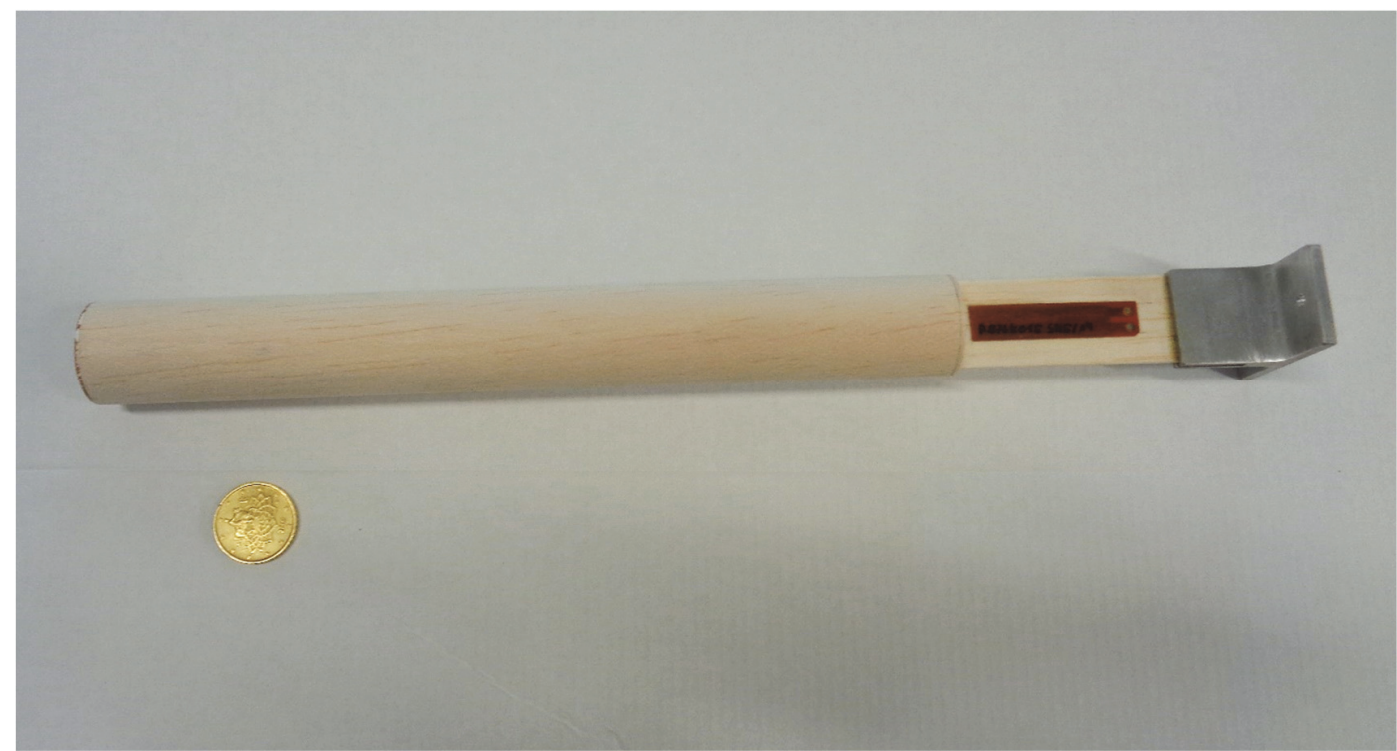

Figure 4: Prototype of the bender.

As can be seen, the configuration of the sensor is composed of three elements:

- A fixed end-support that in aluminum;

- A piezoelectric bender in Kapton (polyimide film) and a piezo-ceramic material;

- An aerodynamic fin in balsa wood.

Regarding the last point, balsa wood has one of the best strength-to-weight ratio of any other readily available materials, it has high strength and low density, and it can be easily shaped, glued, and painted. For these reasons, it is the natural choice in the hobby world.

\section{PiezoeleCtric COMPONENT SELECTION CRITERIA}

he piezoelectric element was a fundamental part of this project. The choice was based on a number of criteria that were set a-priori. The criteria are resumed as follows:

1 - The piezoelectric component has to meet certain conditions with the sensor scope and conception (dimensions and bending capacity);

- The delivery time of the components was critical, since it was necessary to meet the scheduling for the prototype realization and the wind tunnel testing

- The after sales support and the possibility to establish and extend a collaboration with the manufacturer was an additional fundamental aspect.

Eventually, the PI Ceramic P-876K015 DuraAct Patch Transducer was chosen, due to the specific technical characteristics, the delivery time and the after-sales considerations.

\section{Prototype ASSEMBLy}

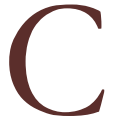

onsidering the materials selected for the final configuration of the prototype and the expected sensitivity of the prototype behavior with respect to the mass distribution along the aerodynamic fin, it was necessary to inquire for a recognized expert in the assembly of aerodynamic components in balsa wood.

The final choice was a local assembler of wood airplane scale models. The proximity of the chosen assembly laboratory allowed to control directly the assembler capacity and machinery, to constantly overview the mounting activity and to decide small changes directly on-site. 
For example, a significant decision was taken on-site, in collaboration with the assembler regarding the geometry and configuration of the aluminum base. In particular, the attachment of the base to the bender was decided to be pinned, something that was not entirely defined in the initial stages.

Due to the complexity of the power extract module emerged by the investigation, the assembling of such circuit was assigned to two external experts who worked independently from each other:

- Dr. Balsi from the Sapienza University of Rome

- Dr. Formisano from Systemdesign s.r.l.

Relevant aspects and technical characteristics linked to the power extract module and considered in the start of the module development were:

- The correlation between the damping and the obtained electrical power;

- The advantages of using a power manager that maximize the electrical energy extracted from the device.

A series of meetings with the external experts was scheduled. In the initial meeting, Dr. Balsi proposed to design an electrical circuit and to perform wind tunnel experiments in order to understand the electro-mechanical coupling behavior. He indicated the electronic components to be acquired in order to assemble the first circuit prototype. Dr. Formisano instead, suggested to characterize the piezoelectric bender and design the circuit in a second phase

After the first wind tunnel tests conducted including the effect of the circuit, an optimization study focusing on the best choice of components and assembly for minimizing the power losses, the final design of the circuit for energy harvesting, data acquisition and wireless transmission was conducted by an additional external assignment to Systemdesign s.r.l.

\section{WIND TUNNEL TESTING}

7 he initial planned strategy regarding the experimental tests was to start with a single consistent experimental campaign, based on the results obtained by the numerical analyses. During that analysis, it was clear that an alternative strategy regarding experimental tests was preferable. A decision was made to divide the experimental test campaign in two sequential steps. Initially, preliminary tests took place for assessing the best aerodynamic configuration. The necessity to conduct this kind of tests was decided also due to the fact that the reliability of CFD analyses was lower than initially expected. The results provided in this first set of experimental tests were valuable since they led to calibrating the numerical models increase their level of reliability to the initially expected one. In a second phase, the originally planned (extended) experimental campaign was carried out on the basis of the device configurations obtained by the calibrated numerical models.

\section{EVOLUTION OF THE MODEL CONFIGURATION}

he evolution of the model configuration is an important aspect of the performed numerical analysis, and led to a configuration that gave very promising results in the testing that followed. In particular, three different aerodynamic fin shapes have been developed and tested as prototypes:

- A circular cylinder shape;

- A rectangular cylinder shape;

- A T-shaped cylinder shape.

At the end, the T-shaped cylinder shape was chosen due to its far better performance over a broad flow range. The following paragraphs describe the evolution of the models.

\section{Circular cylinder model development}

Even before the project started, the numerical analyses focused on a configuration characterized by a rectangular aerodynamic fin. This hypothesis for was based on corroborated literature (in particular [10]) and experience gained by the authors. At a certain point, a significant feedback was received by aerodynamic experts at the INVENTO 2014 conference in Genova, where one of the project investigators presented results from the initial configuration [19]. On the basis of this feedback, it was decided to investigate different shapes and materials, in order to enhance the vibrations of the model, including a T-shape and an H-shape aerodynamic fin. Further discussions between the project investigators and researchers from the UNIFI-CRIACIV, led to a further change in the shape of the fin. The most promising shape was found to be a 
circular section shape one. An additional modeling activity led to the definition of the fin dimensions. Since the beginning the choice of the material was balsa wood.

\section{Rectangular section shape model development}

Among the investigated shapes, one with a rectangular section was considered and later built as a prototype. The original idea was to choose the length side ratio $\mathrm{L} / \mathrm{D}=1$ (square section). This hypothesis for the geometry of the FIN was based on numerical testing previously carried out. Following Investigations made by Mr. Biscarini, the length side ratio was increased to 3 in order to avoid instability phenomenon as galloping. However, after further investigation it was chosen to have a length side ratio of 3.5 in order to avoid problem related to the strong variation of the Strouhal number for length side ratio between 2.8 and 3.3 that make very cumbersome the determination of the vortex shedding frequency.

\section{T-section shape model development and final choice}

Initially, based on corroborated literature and experience gained by the project investigators, also before the project commence, it was thought to develop an $\mathrm{H}$-section shape. However, after further investigation a choice was made to change geometry to a T-section. Due to the lack of literature information about the fluid dynamics behavior of this shape was chosen to design the prototype based on the information obtained by the CNR-DT 207/2008 [20] and numerical analysis. The sensor has been tested in (simulated) real conditions inside the wind tunnel (Fig. 5), demonstrating the energy capacity over a broad flow range typical of HVAC tubes $\left(3-6 \mathrm{~m} / \mathrm{s}^{2}\right)$. Fig. 6 shows the power/flow correlation and the comparison with the numerical results.
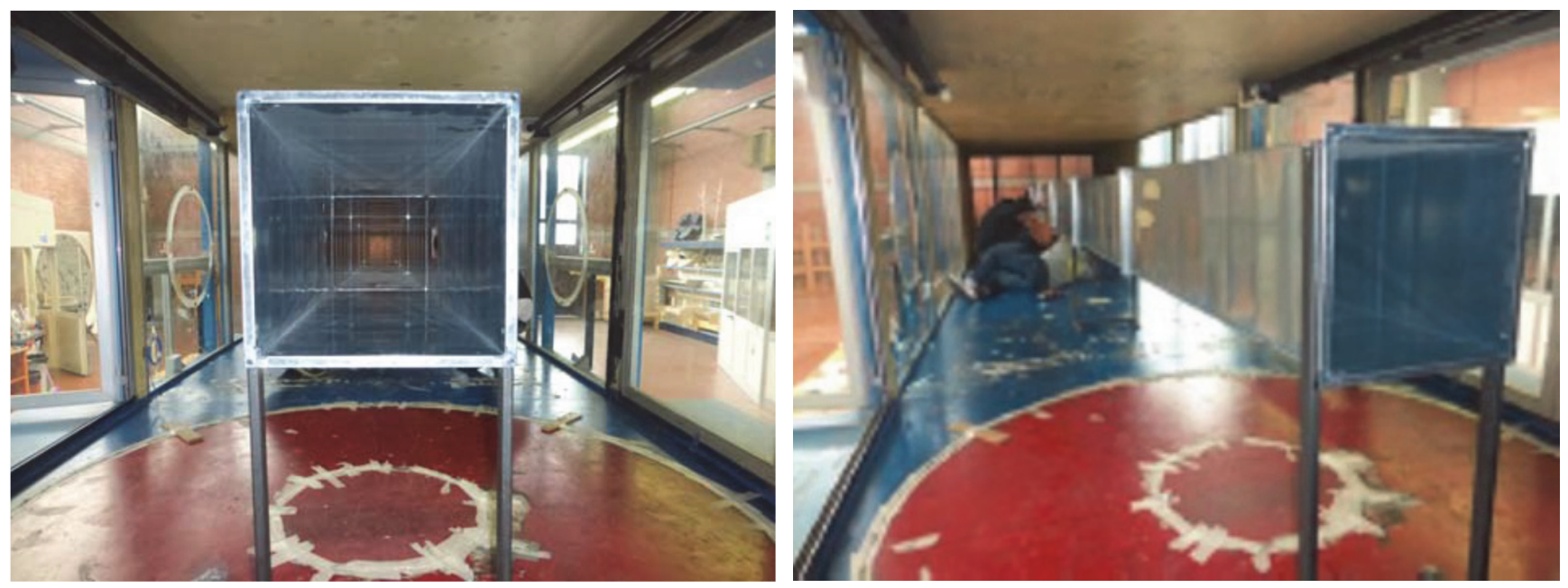

Figure 5: Wind tunnel testing inside a simulated HVAC environment.

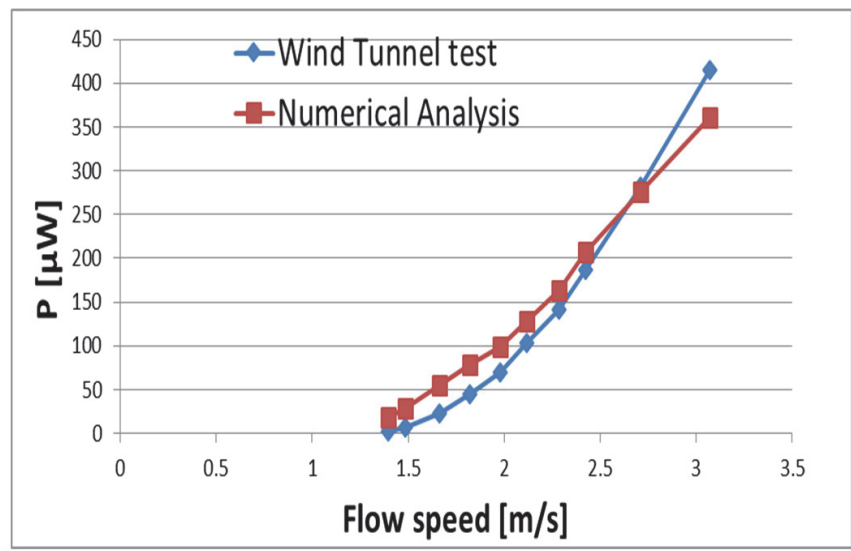

Figure 6: Power/Flow correlation for the T-Shape section.

In a close to production form, the sensor is equipped with the following parts: 
- Piezo Systems Inc Std QM 303 piezoelectric patch

- Microchip MRF89XA multi-channel FSK/OOK transceiver

- Measurement Specialties HTU21D digital temperature and humidity sensor with custom components

It is foreseen that some additional cost-saving will occur for the production version using gross-market components. Fig. 7 shows the blueprint for the final design of the sensor casing and of the communication dongle.

The sensor has already been studied for easy and not-invasive installation inside HVAC tubes, by means of a magnetic base, using common tools, while the cable free operation further facilitates the installation.

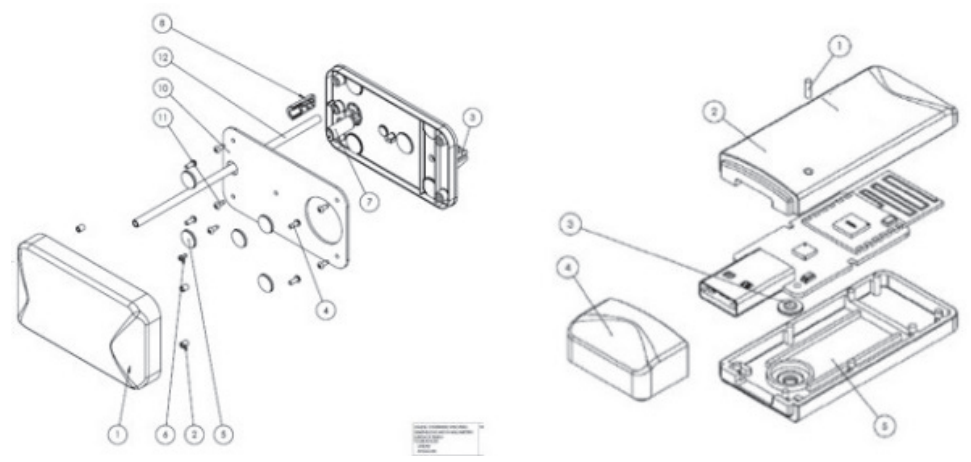

Figure 7: Sensor and usb dongle components blueprints.

\section{MARKET APPROACH}

$\mathrm{n}$ important aspect for the project was the correct market approach since part of the development was aiming at real life applications. In fact, to the authors' knowledge, this is one of the few energy harvesting sensors worldwide that reached after the end of the project a very high maturity level.

\section{Unique selling proposition and market potential}

The developed sensor will be the first mass market energy harvesting sensor based on wind flow excitation, if not one of the very first commercially available vibration energy harvesters. Vibration energy harvesters have been studied thoroughly in the last years, but none of them has been tied to a specific application as in this case. The principal innovation of the sensor is that it produces more power than sensors already in the market, and it is designed specifically for airflow environments, typical of HVAC tubes. This was key marketing strength of the product, since it can be a game-changing asset.

The unique proposition lies to the fact that:

- In general, existing sensors are either mains-powered or autonomous. The latter, use either batteries or an EH module that harvests small amounts of energy, principally using the temperature differential or solar cells. The proposed sensor harvests a higher amount of energy from air flow, and thus has a higher autonomy, something that can lead to a higher sampling rate, and as a consequence, to further reduction in the HVAC energy consumption.

- Regarding the specific application (in HVAC systems), the above mentioned commonly implemented EH methods (based on temperature differential or solar cells) are not efficient since they require specific conditions that are not always present in HVAC systems: for example, solar cells-based EH systems imply the exposition of the cells to the solar or artificial light. In this sense, the proposed sensor is more appropriate since it generates energy precisely from an intrinsic characteristic of HVAC systems (airflow inside the ducts).

The principal competitors identified in HVAC and business automation in general are:

- EnOceanTM ECT 310 Perpetuum

- POWERCASTTM P1110 Powerharvester Receiver

- Distech ControlsTM SR65 AKF - Duct Temperature

These sensors are powered by thermal differential or light cells. EnOceanTM ECT 310 Perpetuum for example, is used for powering battery-less EnOceanTM radio modules by Thermal Energy. In Tab. 2, a brief comparison of the specific piezoelectric harvester is provided with two principal competitors based on EH from temperature differential and solar cells. The comparison is not straightforward, since competitor EH sensors have a very low intermittency due to the lower 
energy production. The sensor's integration inside an HVAC system is straightforward, since in the HVAC duct, the airflow circulation is continuous.

\begin{tabular}{|c|c|c|c|}
\hline & Piezoelectric EH & $\begin{array}{l}\text { EH from } \\
\text { temperature } \\
\text { differential }\end{array}$ & EH from solar cells \\
\hline $\begin{array}{l}\text { Harvested Energy } \\
(\mu \mathrm{W})\end{array}$ & $200 \mu \mathrm{J}$ & $20 \mu \mathrm{J}$ & $20 \mu \mathrm{J}$ \\
\hline External factors & $\begin{array}{l}\mathrm{NO} \text { (Flow induced } \\
\text { vibration intrinsic to } \\
\text { HVAC systems) }\end{array}$ & $\begin{array}{l}\text { A temperature } \\
\text { differential is } \\
\text { necessary }\end{array}$ & $\begin{array}{l}\text { Artificial light is } \\
\text { necessary }\end{array}$ \\
\hline
\end{tabular}

Table 2: Energy harvesting sensor comparison.

From an initial comparison, the harvested power of the sensor is much higher than the competition, harvesting 10-15 times more energy (in the order of 2-4 $\mathrm{mW}$ for HVAC flows), while the price is foreseen to be higher than the competition, something that reflects the relative advantages.

Since self-powered wireless sensors are retailed as a single product to be integrated in the wireless sensor network (WSN) during the design phase of the HVAC and its control system, the sensor will enter in the market as an innovative and efficient device. Focusing on the market value chain (Fig. 8), the producers of Humidity and Temperature sensors represent the first element of the chain. These sensors are a solid part of technologies for smart buildings. Two pertinent examples of these technologies are the wireless network architecture for the data acquisition and the energy harvesting modules for autonomous wireless sensors, which is precisely the location in the value chain of this sensor. These technologies are integrated in HVAC automatic control systems with the goal to optimize the building consumption, which is one of the targets of Building administrators and owners.

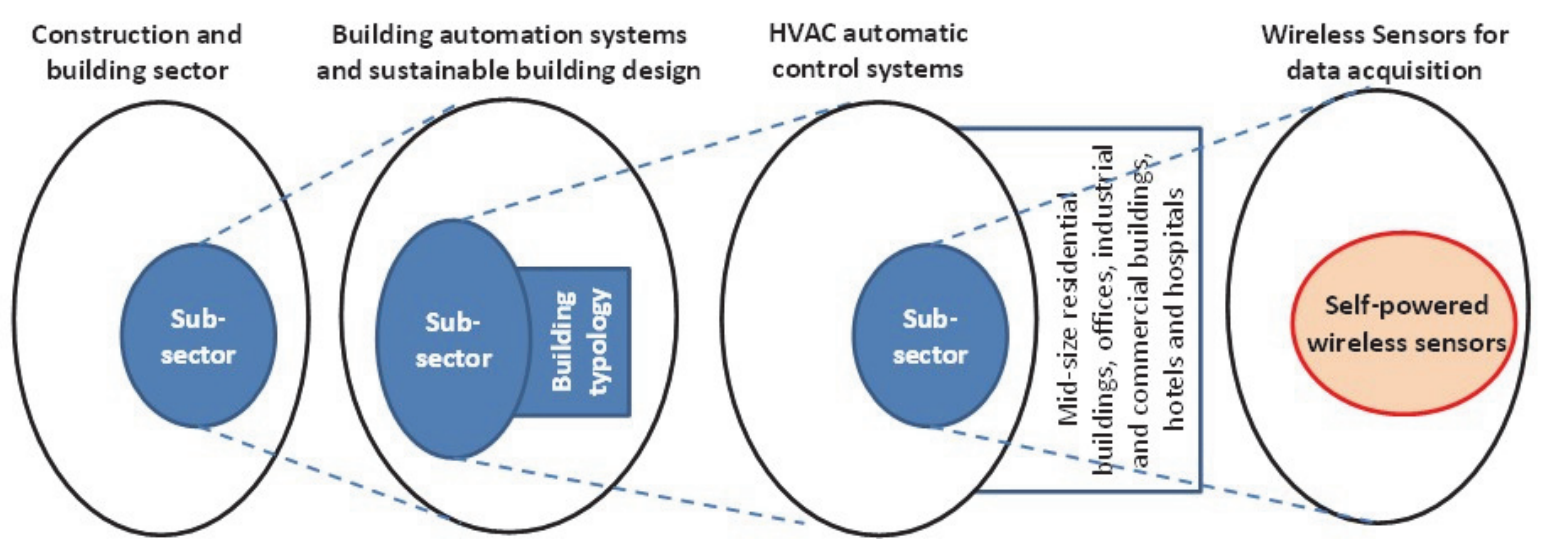

Figure 8: Market sectors for the EH device.

\section{IPR (Intellectual Property Rights)}

The sensor is a highly innovative product and will be one of the first modular and out-of-the-box EH devices for office automation applications based on piezoelectric material. A European Patent application has been applied (European Patent Application: EP2953259 - 2015-12-09). The principal claim is of a self-powered device of specific characteristics for the detection of environmental and/or structural parameters and for transmitting such data in wireless mode.

\section{Promotion strategy}

The principal promotion strategy aimed to the sensor becoming recognizable in the HVAC automation systems scene (designers and installers), following two principal directions: entering an association of produces and selling directly to customers. Entering a consortium operating in smart systems and automation such as the ZigBee ${ }^{\circledR}$ Alliance offers some noteworthy advantages (among else, it is open both to enterprises and research companies). The option would be to participate in the alliance as "Adopter", and this will bring benefits for what regards marketing and promotion activities. 
The following exhibitions and events have been attended (spanning an arc of one year in the product development) for obtaining feedback on the practical employment of the sensor and perform brokerage activities.

- Climatherm - Energy 201625 - 28 February 2016, Athens Metropolitan Expo "Together for an energy sustainable future", with over 15.000 visitors (businesses, technicians, researchers, engineers, architects, hoteliers etc.) featuring the latest trends, meet suppliers and useful business contacts

- Energy Harvesting \& Storage Europe (Berlin April 28-29 2016), the biggest energy harvesting and building automation fair in Europe in 2016. It features big brands discussing their needs and experiences, new product launches, world first announcements and insightful analyst presentations.

- EU Brokerage Event on KET in Horizon 2020, Parkhotel, Mainz, Germany Thursday, 12 May 2016, focusing on: Key Enabling Technologies - KETs Nanotechnologies and Advanced Materials, Biotechnologies, Advanced Manufacturing and Processing (NMBP).

\section{STAGE OF DEVELOPMENT}

$\mathrm{O}$

ne of the project task was to demonstrate the technical maturity of the sensor and the technology. This was done through an assessment in terms of Technology Readiness Levels (TRL). At the project start the TRL level (as formulated in [21]) was assessed as 2 ("Technology concept and/or application formulated). At the end of the project the TRL was raised to 6 ("Model demonstrating the critical functions of the element in a relevant environment"). The product has been thoroughly studied, and critical issues have been assessed in a numerical simulation and experimental testing in wind tunnel, including the testing of close to real conditions (inside an HVAC tube section placed in wind tunnel).

\section{CONCLUSIONS}

$\checkmark$ his paper focuses on the development of an EH device for smart buildings. Compared to other self-powered temperature sensors, the developed sensor is more efficient, since it is placed inside HVAC ducts and harvest a higher amount of energy from airflow, without maintenance costs. Highlights from the development phases are presented and commented, highlighting the complexities in such a complex project. Among the challenges addressed, were aspects outside the expertise of the project developers, such as performing a market analysis or defining marketing strategies. A last issue relates to a technical part. In particular, in the performed preliminary analyses some scientific and technical issues remained open, and more precisely, the form of the aerodynamic fin. In fact, initially, a cylindrical shape was chosen as the most adequate, and it was kept for most part of the project. Only the last aerodynamic campaign at the CRIACIV wind tunnel clarified these aspects, and led to using a T-shaped part, which proved to have numerous advantages, in particular for what regards the energy harvesting flow band. Even though the project is now terminated under the ESA BIC umbrella, the developers are committed in promoting the project in further research or implementation activities.

\section{ACKNOWLEDGMENTS}

$\checkmark$ he realization of a multidisciplinary project as the one described in this paper requires the collaboration between different disciplines and different authors. Dr. Petrini from the Sapienza University of Rome was the principal investigator for the technical/scientific part of the project. During the 24 months, 160 expert hours were used with ESA BIC Lazio specialists (Ms Pasqualina Cedrone, and ESA BIC director Mr Roberto Giuliani) that included 22 progress meetings. Dr. Balsi from the Sapienza University of Rome and Dr. Formisano from SystemDesign s.r.l. are acknowledged for their contribution to the electrical design of the sensor, and Mr. Biscarini is acknowledged for performing numerical (FEM and CFD) analyses.

\section{REFERENCES}

[1] Gkoumas, K. (2012). Energy harvesting in bridges and transportation infrastructure networks: state of art, recent trends and future developments. Proceedings of the Sixth International IABMAS Conference, pp. 1527-1533. 
[2] Matiko, J.W., Grabham, N.J., Beeby, S.P. and Tudor, M.J. (2013). Review of the application of energy harvesting in buildings. Measurement Science and Technology, 25(1).

[3] Park, G., Rosing, T., Todd, M.D., Farrar, C.R. \& Hodgkiss, W. (2008). Energy Harvesting for Structural Health Monitoring Sensor Networks. ASCE Journal of Infrastructure Systems, 14(1), pp. 64-79

[4] Arangio, S., Bontempi F., Ciampoli M. (2011). Structural integrity monitoring for dependability, Structure and Infrastructure Engineering, 7(1), pp. 75-86.

[5] Gkoumas, K., Petrini, F., Bontempi, F. (2017). Piezoelectric vibration energy harvesting from airflow in HVAC (Heating Ventilation and Air Conditioning) systems Procedia Engineering 199, pp. 3444-3449.

[6] Petrini, F., Gkoumas, K. (2018). Piezoelectric energy harvesting from vortex shedding and galloping induced vibrations inside HVAC ducts Energy and Buildings 158, pp. 371-383.

[7] Morvaj, B, Lugaric, L. and Krajcar, S. (2011) Demonstrating smart buildings and smart grid features in a smart energy city. Proceedings of the 2011 3rd International Youth Conference on Energetics (IYCE), pp.225-232.

[8] Harb A. (2011) Energy harvesting: State-of-the-art. Renewable Energy, 36(10), pp. 2641-2654.

[9] Wu, N., Wang, Q. and Xie, X. (2013). Wind energy harvesting with a piezoelectric harvester. Smart Materials and Structures, 22(9).

[10] Weinstein, L. A., Cacan, M. R., So, P. M. and Wrigth, P. K. (2012). Vortex shedding induced energy harvesting from piezoelectric materials in heating, ventilation and air conditioning flows. Smart Materials and Structures. 21(10).

[11] Gkoumas, K., Petrini, F., De Gaudenzi, O. (2012). Energy harvesting applications in transportation infrastructure networks, Procedia - Social and Behavioral Sciences 48, pp. 1097-1107.

[12] Gkoumas, K., Petrini, F., Bontempi, F. (2012). Energy harvesting for the life cycle of structures and infrastructures: state of art, recent trends and future developments, 3rd International Symposium on Life-Cycle Civil Engineering (IALCCE 2012), Vienna, Hofburg Palace, Austria, October 3-6.

[13] Petrini, F., Gkoumas, K., De Gaudenzi, O. (2012). Wind energy harvesting in civil engineering systems, Joint Conference of the Engineering Mechanics Institute and 11th ASCE Joint Specialty Conference on Probabilistic Mechanics and Structural Reliability (EMI/PMC 2012), Notre Dame, USA, June 17-20.

[14] Petrini, F., De Gaudenzi, O., Gkoumas, K. (2012). An energy harvesting application in a long span suspension bridge, 3rd International Symposium on Life-Cycle Civil Engineering (IALCCE 2012), Vienna, Hofburg Palace, Austria, October 3-6.

[15] Ferri, S., Gkoumas, K., Petrini, F. and Bontempi, F. (2014). Flow-induced energy harvesting: conceptual design and numerical analyses of a piezoelectric bender for smart building applications, Proceedings of the 3rd International Workshop on Design in Civil and Environmental Engineering, Jensen \& Mary Kathryn Thompson Editors, pp. 146156.

[16] Gkoumas, K. (2012). Special Session: Energy harvesting in Bridges and Transportation Infrastructure Networks, 6th International Conference on Bridge Maintenance, Safety and Management (IABMAS 2012), Stresa, Lake Maggiore, Italy.

[17] Manenti S., Petrini F. (2010). Dynamic analysis of an offshore wind turbine: Wind-waves nonlinear interaction, Proceedings of the 12th International Conference on Engineering, Science, Construction, and Operations in Challenging Environments - Earth and Space 2010, Honolulu, HI, United States, pp.14-17 March 2010, Pages 20142026.

[18] Biscarini, G., Petrini, F., Gkoumas, K. and Bontempi, F. (2016). Piezoelectric EH from flow-induced structural vibrations, IN-VENTO 2016 XIV Conference of the Italian Association for Wind Engineering, Terni, Italy.

[19] Petrini, F., Gkoumas, K., Bontempi, F. (2014). Piezoelectric Energy Harvesting under Air Flow Excitation. IN-VENTO 2014, XIII Conference of the Italian Association for Wind Engineering, Genova (Italy).

[20] CNR-DT 207/2008. (2008). Guidelines on Actions and Effects of Wind on Structures (in Italian).

[21] ESA. (2018). Technology Readiness Level (TRL) - The ESA Science Technology Development Route. Available at: http://sci.esa.int/sci-ft/50124-technology-readiness-level 